\title{
Reducing Groundwater Overexploitation with Improving Operational Performances of Irrigation Canal
}

\author{
S.M. Hashemy Shahdany ${ }^{1}$, S. Javadi ${ }^{1 *}$, A. Neshat ${ }^{2}$, H. Salmani $^{3}$, M. Morady Kondory ${ }^{3}$ and M. Malmir ${ }^{3}$
}

\begin{abstract}
Nearly 90 percent of global groundwater supported irrigated areas are those that have conjunctive use of both surface and groundwater. A major driver behind the use of groundwater in these regions, beside surface water availability issue, is the poor operational performance of the surface irrigation schemes. Therefore, they intensively extract water and continuously deteriorate the aquifers. The current study focuses on six main irrigation districts that are located in Zayandeh-Rud River Basin (ZRB), in the central part of Iran, where a total area of 200,000 hectares is irrigated using surface water in conjunction with groundwater. To improve the performance of the irrigation networks for each of these districts, three operational model alternatives including fully automated systems were incorporate. Each of these models is designed and run for each of the six districts separately. The results of this study point to $15 \%$ to $25 \%$ reduction in operational water losses depending on the alternatives. These potentially reduced water losses are then available to be used in the agricultural sector that can result in reducing the groundwater extraction up to 300 (Million Cubic Meters (MCM).
\end{abstract}

Index Terms-Automation, Canals Operation, Groundwater Overexploitation.

\section{INTRODUCTION}

Nearly 90 percent of global groundwater supported irrigated areas are those that have conjunctive use of both surface water and groundwater [1]. However, groundwater will remain the ultimate source of irrigation, due to the unreliable performance of the surface water distribution systems in arid and semi-arid areas (Burt, 2013; Singh, 2014).

Substantial investments have been made in developing canal networks for appropriate allocation of the surface water to the farms in the arid and semi-arid regions. However reliable water distribution has not been achieved due to poor canal operation (Burt, 2013). Accordingly, modernization, rehabilitation, and renovation of irrigation districts, in both farm scales and off-farm water management, needs to be focused on the long-term demand management. Previous studies have shown that automatic operational services can provide consistent and

S. M. Hashemy Shahdany and S. Javadi ${ }^{*}$ bot are with the Aburaihan Campus, University of Tehran, Pakdasht, Tehran, Iran

A. Neshat is with the Department of Environment and Energy, Science and Research Branch, Islamic Azad University, Tehran, Iran

H. Salmani, M. Morady Kondory and M. Malmir Civil Engineering, Tehran, Iran. reliable water delivery to the entire water users, from those located at the most upstream laterals to the end users of the main canal, due to the more reliable performance of the systems (Clemmens, 2012; Guan et al., 2011; Hashemy Shahdany et al., 2015). An intelligent operation of the canals, provided by the optimal control systems, can significantly reduce the operational water losses within the canals, and consequently lead to conserving the higher amount of water.

Automation of the canal system requires implementing advanced real-time control algorithms to deal with the complicated interactions between control objectives and the water saving operational strategy. In this study, two configurations of the decentralized and centralized control system are designed and tested. Also, impacts of performance improvement of the canal systems on reducing operational water losses are thoroughly investigated. Accordingly, the Proportional Integral (PI) and Model Predictive Control (MPC) are selected as the decentralized and centralized configurations, respectively. Application of PI decentralized control systems, acting as a Single Input - Single Output (SISO) system, is previously investigated in different irrigation canals (Burt, 1999; Hashemy et al., 2013; van Overloop et al., 2005; Wahlin and Clemmens, 2006). Model Predictive Control (MPC), which has been widely applied in the studies related to canal automation (Maestre and Negenborn, 2014; Van Overloop et al., 2010; Zafra-Cabeza et al., 2011a), is employed. MPC is a model-based control approach, combining feedbacks control on measured water levels at different locations along the canal, with feedforward control dealing with predictable disturbances and optimal control to provide a highly intelligent operational performance of the canal network (Camacho and Bordons, 2004).

The present study focuses on Zayandeh-Rud River Basin (ZRB), a sub-basin of Central Plateau Basin (CPB) in the central part of Iran with six main irrigation network districts. This study hypothesizes that improved canal operational management through automation techniques can improve surface water distribution system, reduce the operational water losses, the groundwater exploitation throughout the six irrigation districts. Procedure for Paper Submission.

\section{STUdy AREA DESCRIPTION}

ZRB is located in central part of Iran, on the east side of the 
Zagros Mountains in Esfahan Province. The Zayanderud River is one of the major rivers in the central part of Iran extending from west to east and draining into the Gave-khuni swamp (Figure 1). The ZRB basin has covering a total area of 41,524 $\mathrm{Km} 2$ and is characterized by its semi-arid climate with 50 to 1,500 $\mathrm{mm}$ average annual precipitation and 1,500 $\mathrm{mm}$ annual evapotranspiration. For this basin, the primary source of water is snowmelt that peaks during spring (Bhadra et al., 2010).

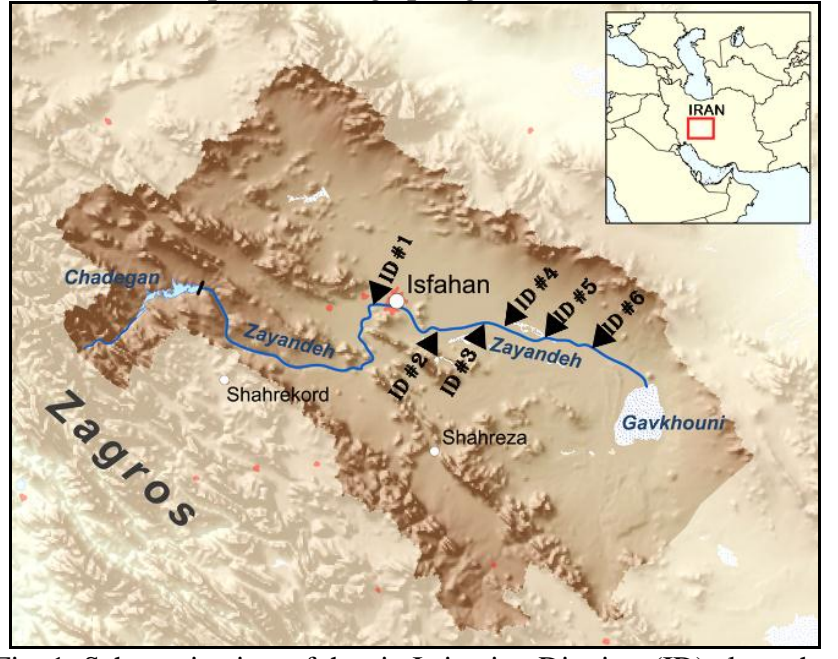

Fig. 1: Schematic view of the six Irrigation Districts (ID) along the Zayendeh-Rud river

Currently, there are six irrigation districts within the basin which are shown in Figure 1. The information including infrastructure, operational, and groundwater abstraction within the six irrigation districts are summrized in Table 1.

TABLE I: SUMMARIZING INFORMATION FROM THE SIX IRRIGATION DISTRICTS

\begin{tabular}{|c|c|c|c|c|c|c|c|}
\hline \multirow{2}{*}{ ID } & \multirow{2}{*}{$\begin{array}{l}\text { Farm } \\
\text { land } \\
\text { (ha) }\end{array}$} & \multicolumn{2}{|c|}{$\begin{array}{l}\text { Conveyance } \\
\text { System }\end{array}$} & \multicolumn{2}{|c|}{$\begin{array}{l}\text { Design } \\
\text { Capacity of } \\
\text { the Main } \\
\text { Canal } \\
(\mathrm{cms})\end{array}$} & \multicolumn{2}{|c|}{$\begin{array}{l}\text { Conveyance system } \\
\text { infrastructure and } \\
\text { operational } \\
\text { management }\end{array}$} \\
\hline & & $\begin{array}{l}\text { lengt } \\
\mathrm{h} \\
(\mathrm{km})\end{array}$ & $\begin{array}{l}\text { type of } \\
\text { lining }\end{array}$ & $\begin{array}{c}\text { Lef } \\
\mathrm{t} \\
\text { Bra } \\
\mathrm{nch}\end{array}$ & $\begin{array}{l}\text { Righ } \\
\mathrm{t} \\
\text { Bran } \\
\text { ch }\end{array}$ & $\begin{array}{c}\text { Main } \\
\text { Regulating } \\
\text { Structures }\end{array}$ & $\begin{array}{l}\text { Main } \\
\text { Off-tak } \\
\text { es }\end{array}$ \\
\hline ID1 & $\begin{array}{c}3300 \\
0\end{array}$ & 95 & $\begin{array}{c}\text { Earthe } \\
n\end{array}$ & 7 & 10 & Check & Check \\
\hline ID2 & $\begin{array}{c}3600 \\
0\end{array}$ & 231 & $\begin{array}{c}\text { Concre } \\
\text { te }\end{array}$ & 12 & - & $\begin{array}{l}\text { Hydro-Mech } \\
\text { anical \& } \\
\text { Duck-Bill }\end{array}$ & $\begin{array}{c}\text { Nyrpic } \\
\text { Modul } \\
\mathrm{e}\end{array}$ \\
\hline ID3 & $\begin{array}{c}1300 \\
0\end{array}$ & 267 & $\begin{array}{c}\text { Concre } \\
\text { te }\end{array}$ & - & 12 & $\begin{array}{l}\text { Hydro-Mech } \\
\text { anical \& } \\
\text { Duck-Bill }\end{array}$ & $\begin{array}{c}\text { Nyrpic } \\
\text { Modul } \\
\text { e }\end{array}$ \\
\hline ID4 & $\begin{array}{c}6500 \\
0 \\
\end{array}$ & 205 & $\begin{array}{c}\text { Concre } \\
\text { te }\end{array}$ & 50 & 15 & $\begin{array}{l}\text { Hydro-Mech } \\
\text { anical }\end{array}$ & $\begin{array}{c}\text { Nyrpic } \\
\text { Modul } \\
\text { e }\end{array}$ \\
\hline ID5 & $\begin{array}{c}3000 \\
0\end{array}$ & 129 & $\begin{array}{c}\text { Concre } \\
\text { te }\end{array}$ & 15 & 15 & $\begin{array}{l}\text { Hydro-Mech } \\
\text { anical }\end{array}$ & $\begin{array}{c}\text { Nyrpic } \\
\text { Modul } \\
\text { e }\end{array}$ \\
\hline ID6 & $\begin{array}{c}4200 \\
0\end{array}$ & 317 & $\begin{array}{c}\text { Concre } \\
\text { te }\end{array}$ & 24 & 24 & Duck-Bill & $\begin{array}{c}\text { Nyrpic } \\
\text { Modul } \\
\text { e }\end{array}$ \\
\hline
\end{tabular}

\section{MethodOLOGY}

Two configurations of the control systems, including the decentralized and the centralized, as two sets of practical alternatives were selected to invesyigated the objectives of the study. This way the potential performance improvement capability of canal operational management to appropriately deliver surface water resources throughout the irrigation districts will be studied.

\section{CANAl Operation Alternatives}

\section{A. Decentralized controller}

Decentralized controller configuration is one of the most practical and widely accepted alternatives in canal automation projects. The decentralized controller is more preferable than centralized one due to its reduced implementation requirements, operational and maintenance complications and costs (Ooi and Weyer, 2008). This Single Input-Single Output (SISO) control system computes the control actions for each gate by considering only measurements taken in the vicinity (van Overloop et al., 2005). In this study, a combination of feedback and feedforward control configurations is used to provide a reasonable operational performance within the controlled canal system. The former manipulates the water level at a gate location, while the latter (i.e., feedforward) adjusts the head-gate based on a known water delivery schedule. Based on the proposed method by (van Overloop, 2006) a low-pass filter is added in series with the designed PI controllers to make a PIF controller. Applying this controller leads to the following calculation of the controlled flow change through the gate (van Overloop et al., 2005):

$$
\Delta Q(k)=K_{p} \cdot\left[e_{f}(k)-e_{f}(k-1)\right]+K_{i} \cdot e_{f}(k)
$$

where is $\Delta Q(k)$ the calculated flow change through a controlled gate, $K_{i}$ and $K_{p}$ are the integral and proportional gains, respectively. According to figure 5, two functional configurations of the PIF controller are employed for the alternatives A6 and A7. In A6, the "upstream control configuration" is utilized, while the "distant downstream configuration" is applied to A7. Implementation of the latter configuration requires a communication system connecting the downstream end of canal sensor to the controller at the upstream side of the pool.

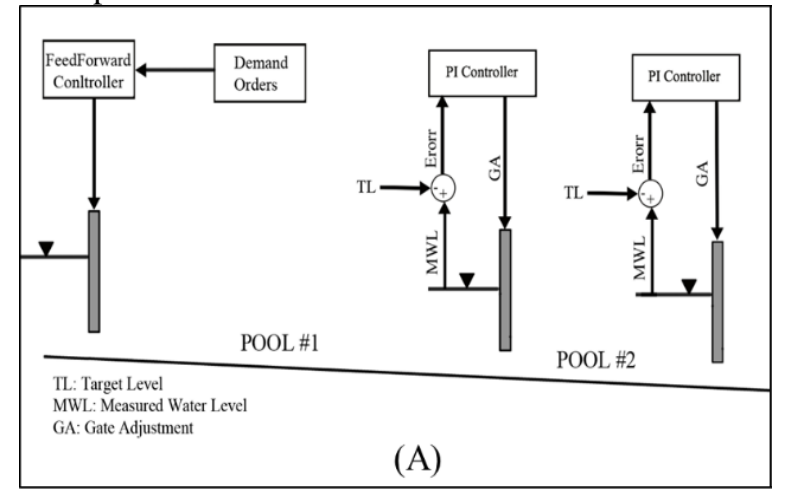

Fig. 2: Decentralized configuration (A) Upstream PIF controller 


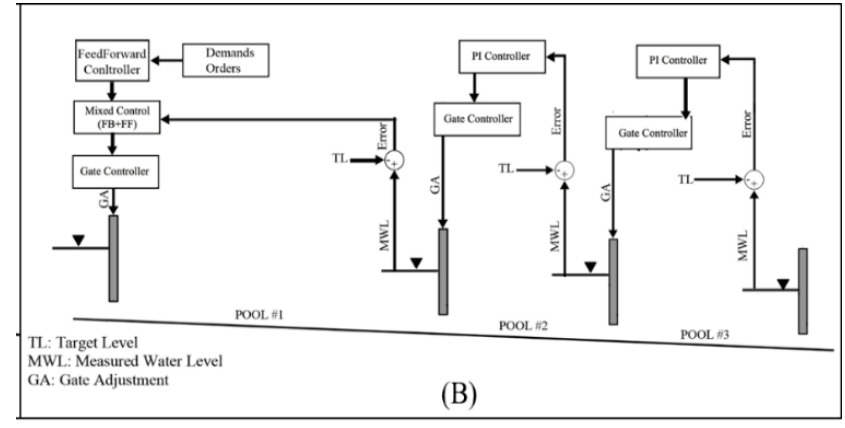

Fig. 3: Decentralized configuration (B) Distant Downstream PIF controller

\section{B. Centralized Controller}

Centralized controller configuration is the system that takes all the variables of the canal systems into account for assigning controlled actions. State variables, including water level at the gate locations, are measured and transmitted to a master control station through communication systems. The gate adjustments are simultaneously calculated by the centralized controller at each time step and sent to the actuators. The centralized control settings are used in A3 alternative, and a schematic view is depicted in Figure 6. In particular, Model Predictive Control (MPC) is designed and tested for the six main canals. This centralized strategy is popular due to its satisfactory operational performance and its capacity of dealing with a broad range of optimization objectives within conveyance and delivery systems, and uncertainties in supplying canal inflow, delay times of water traveling, and structural and system variables constraints [1]. To achieve this goal, the controller employs the present state of variables of the canal system, an internal model simulating the hydraulic behavior of the canal, and an objective function identifying the deviation of the canal system from the target conditions and control objectives. The objective function of the MPC, where penalizes the deviation of the current regime from the reference during the next $N_{h}$ time steps, is presented as [2]:

$J\left(U, x_{0}\right)=\sum_{k=0}^{N_{k}-1}\left(x^{T}(k) Q x(k)+Q_{l} x(k)+u^{T}(k) R u(k)\right)$

$+x^{T}\left(N_{h}\right) Q x\left(N_{h}\right)+Q_{l} x\left(N_{h}\right)$,

where $x(k)$ is the state of the system; $u(k)$ represents the controlled variable matrix; $Q, Q_{l}$ and $R$ are constant weighting matrices of the proper size; $N_{h}$ is the prediction horizon; $\quad x_{0}$ is the current state; and $U=\left(u(0), u(1), \ldots, u\left(N_{h}-1\right)\right)$ is the sequence of values of the manipulated variables.

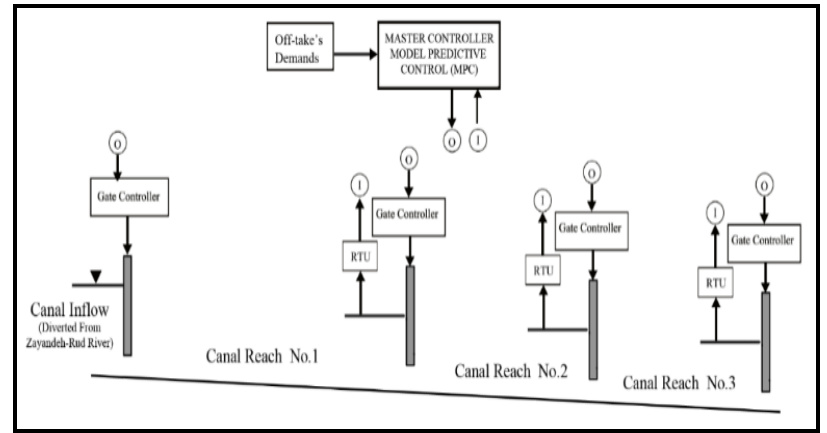

Fig. 4: Centralized Model Predictive Controller scheme

\section{OPERATIONAL PERFORMANCE INDICATORS}

The performance indicator for this study is the ability of the controller to meet the primary objective which is reducing the operational water loss. Therefore, the water conveyance and distribution adequacy (PA) and equity (PE) criteria, proposed by [3], are employed. The adequacy of delivery (PA) represents sufficient water delivery according to the agreement between the canal authorities and Water User Associations (WUAs) representatives to meet the farmer's demands at each off-takes along the main canal. Otherwise stated, the adequacy indicator shows the ability of operation method to deliver enough water to users that is defined as follow [4]:

$$
\begin{aligned}
P_{A}= & \frac{1}{T} \sum_{T}\left[\frac{1}{R} \sum_{R} P_{a}\right], \\
& \text { with }\left\{\begin{array}{c}
P_{a}=\left(\frac{Q_{D}}{Q_{R}}\right) \text { if } \quad Q_{D}<Q_{R} \\
P_{a}=1 \quad \text { Otherwise }
\end{array}\right.
\end{aligned}
$$

Where $Q_{D}$ and $Q_{R}$ respectively are the total and required amounts of delivered water to an off-take at each time step $(\mathrm{m} 3 / \mathrm{s}) ; P_{A}$ values closer to unity show reasonable operational performance from the adequacy perspectives.

The operational performance from an equity perspective is assessed by determining the degree of variability in relation to water delivery from all the off-takes over a canal reach. The equity indicator was defined in [3] as:

$$
P_{E}=\frac{1}{T} \sum_{T} C V_{R}\left(\frac{Q_{D}}{Q_{R}}\right)
$$

Where $C V_{R}\left(Q_{D} / Q_{R}\right)$ is the spatial variation of the ratio $Q_{D} / Q_{R}$ along the canal reach. $P_{E}$ values closer to zero show a greater degree of equity over the canal reach.

\section{RESUlTS AND DISCUSSION}

The models of the operational alternatives A1, A2 (decentralized configurations), and A3 (centralized) were designed and coupled with the developed main canal hydraulic model. The operational performance of the alternatives was then evaluated through the performance indicators and compared with the current condition. For every irrigation district, operational performance indicators of adequacy and equity were determined by assessing water delivery activities within the main canal from the first pool at the upstream to the 
last pool at the downstream. The results are presented in Figure 5 .

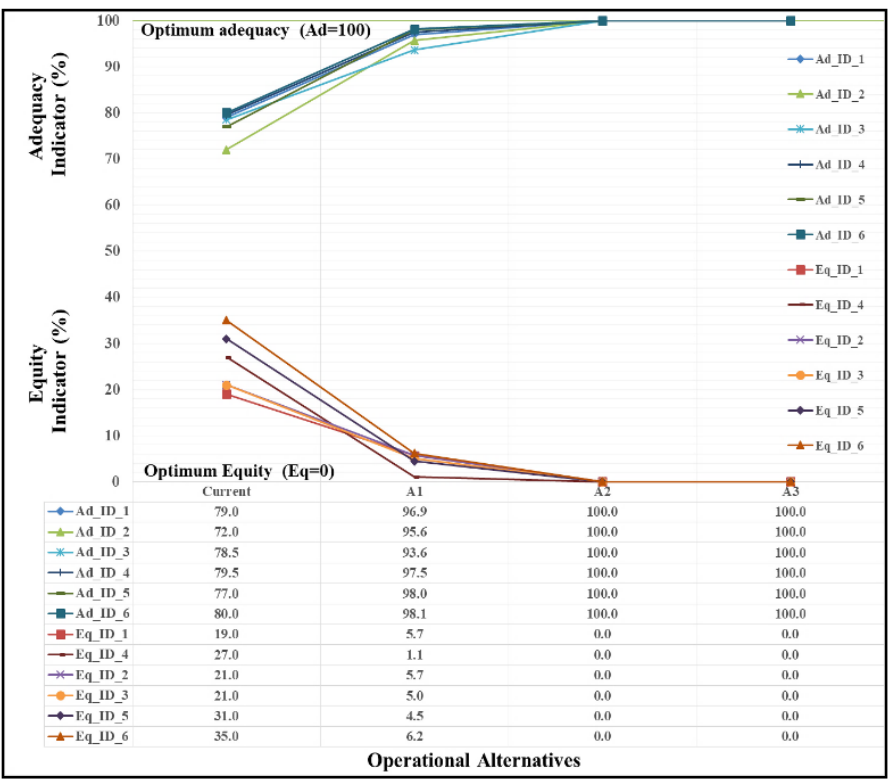

Fig. 5: Calculated performance assessment indicators for the current operation versus employing the alternatives

According to Figure 5, the current operational condition of the six irrigation districts (ID No.1 through ID No.6) shows a poor water distribution within the main canal both regarding adequacy and equity. The assessed adequacy indicator values range between $72 \%$ to $80 \%$ in ID\#2 and ID\#6, respectively. This result reveals a poor water delivery condition that indicates the farmers need to deal with up to $28 \%$ deficit. Indeed, this $28 \%$ deficit is the amount of water that most likely farmers will extract from the groundwater wells to meet the crop water demand. The equity indicator is ranging from $19 \%$ to $35 \%$ in ID\#1 and ID\#6, respectively. These values also indicate a poor operational status (based on the classification of the indicator provided by (Molden et al., 2007)) of the current condition leading to an unreasonable water distribution between the upstream off-takes and downstream ones. Therefore based on the current values of operational performance indicators, there is a high potential for implementation of the automation techniques.

Analysis of the alternatives (A1 through A3) shows improvements in both equity and adequacy indicators. In fact, alternatives $\mathrm{A} 2$ and $\mathrm{A} 3$ delivered water to the users without any imperfection (100\% adequacy and 0 equity). The results showed that the current operational status of irrigation districts could noticeably be improved under normal operational by implementing the alternatives. The ability of automatic canal control system in dealing with operational complexities is investigated and demonstrated for a broad range of water shortages scenarios in the following sections.

\section{SUMMARY AND CONCLUSION}

The contents of the journal are peer-reviewed and archival. The journal Journal of Advances in Computer Networks publishes scholarly articles of archival value as well as tutorial expositions and critical reviews of classical subjects and topics of current interest.

An extensive attempt was carried out to investigate the application and implementation of various modernization alternatives within the districts and the potential managerial and environmental impacts. Three operational options (A1 to A3), using automatic control systems, were developed and assessed in this study. The potential of each alternative to increasing the reliability of water distribution and efficiency of the water conveyance and delivery by reducing operational loss within canals was quantitatively assessed. Operational improvements are compared with the current operational state of the districts.

Application of automatic control systems, including centralized MPC, enables the authorities of the district to develop various strategic plans regarding the operational improvement according. Based on the current policies followed by Isfahan water regional authorities, and the top priorities of the ZRB watershed, the potential operational improvement through operational modernization can be used to substitute the groundwater extraction.

\section{ACKNOWLEDGMENT}

Authors would like to acknowledge the financial support for this study provided by the Esfahan Regional Water Authority using the research project (ref. 96/128).

\section{REFERENCES}

[1] P.S. Thenkabail, C.M. Biradar, P. Noojipady, V. Dheeravath, Y. Li, M. Velpuri, M. Gumma, O.R.P. Gangalakunta, H. Turral, X. Cai, Global Irrigated Area Map (GIAM), Derived from Remote Sensing, for the end of the last Millennium, International Journal of Remote Sensing, 30 (2009) 3679-3733.

https://doi.org/10.1080/01431160802698919

[2] C.M. Burt, The Irrigation Sector Shift from Construction to Modernization: What Is Required for Success?, Irrigation and Drainage, 62 (2013) 247-254.

https://doi.org/10.1002/ird.1703

[3] A. Singh, Simulation-Optimization Modeling for Conjunctive Water Use Management, Agricultural Water Management, 141 (2014) 23-29. https://doi.org/10.1016/j.agwat.2014.04.003

[4] A.J. Clemmens, Water-Level Difference Controller for Main Canals, Journal of Irrigation and Drainage Engineering, 138 (2012) 1-8. https://doi.org/10.1061/(ASCE)IR.1943-4774.0000367

[5] G. Guan, A.J. Clemmens, T.F. Kacerek, B.T. Wahlin, Applying Water-Level Difference Control to Central Arizona Project, Journal of Irrigation and Drainage Engineering, 137 (2011) 747-753.

[6] S.M. Hashemy Shahdany, J.M. Maestre, P.J. van Overloop, Equitable Water Distribution in Main Irrigation Canals with Constrained Water Supply, Water Resources Management, 29 (2015) 3315-3328. https://doi.org/10.1007/s11269-015-1000-4

[7] C.M. Burt, Current Canal Modernization from an International Perspective, in: Proceedings USCID-Workshop, Phoenix, Arizona, 1999.

[8] S.M. Hashemy, M.J. Monem, S. Isapoor, P.J. van Overloop, Using in-Line Reservoir Operational Strategy to Improve Dez Main Irrigation Canal Performance, Irrigation and Drainage, 62 (2013) n/a-n/a.

[9] P.J. van Overloop, J. Schuurmans, R. Brouwer, C.M. Burt, Multiple-Model Optimization of Proportional Integral Controllers on Canals, Journal of Irrigation and Drainage Engineering, 131 (2005) 190-196. https://doi.org/10.1061/(ASCE)0733-9437(2005)131:2(190)

[10] B.T. Wahlin, A.J. Clemmens, Automatic Downstream Water-Level Feedback Control of Branching Canal Networks: Theory, Journal of Irrigation and Drainage Engineering, 132 (2006) 198-207. https://doi.org/10.1061/(ASCE)0733-9437(2006)132:3(198) 
[11] P.J. Van Overloop, R.R. Negenborn, B.D. Schutter, N.C. Giesen, Predictive Control for National Water Flow Optimization in The Netherlands, in: R.R. Negenborn, Z. Lukszo, H. Hellendoorn (Eds.) Intelligent Infrastructures, Springer Netherlands, 2010, pp. 439-461. https://doi.org/10.1007/978-90-481-3598-1_17

[12] A. Zafra-Cabeza, J.M. Maestre, M.A. Ridao, E.F. Camacho, L. Sanchez, Hierarchical Distributed Model Predictive Control for Risk Mitigation: An Irrigation Canal Case Study, in: American Control Conference (ACC), 2011, 2011, pp. 3172-3177. https://doi.org/10.1109/ACC.2011.5990923

[13] J.M. Maestre, R.R. Negenborn, Distributed Model Predictive Control Made Easy, Springer, 2014. https://doi.org/10.1007/978-94-007-7006-5

[14] E.F. Camacho, C. Bordons, Model Predictive Control in the Process Industry, Springer-Verlag, London, England, 2004.

[15] A. Bhadra, A. Bandyopadhyay, R. Singh, N.S. Raghuwanshi, An Alternative Rotational Delivery Schedule for Improved Performance of Reservoir-based Canal Irrigation System, Water Resources Management, 24 (2010) 3679-3700.

[16] IDE, Master Plan of Countermeasures to Prevention and Control Dust Phenomenon in Central Isfahan, in, Isfahan Department of Environment, Isfahan Department of Environment, 2015, pp. 199.

[17] S.K. Ooi, E. Weyer, Control Design for an Irrigation Channel from Physical Data, Control Engineering Practice, 16 (2008) 1132 - 1150.

[18] P.J. van Overloop, Model Predictive Control on Open Water Systems, IOS Press, 2006.

[19] A. Zafra-Cabeza, J.M. Maestre, M.A. Ridao, E.F. Camacho, L. Sánchez, A Hierarchical Distributed Model Predictive Control Approach to Irrigation Canals: A Risk Mitigation Perspective, Journal of Process Control, 21 (2011) 787-799. https://doi.org/10.1016/j.jprocont.2010.12.012

[20] D. Molden, T. Gates, Performance Measures for Evaluation of Irrigation-Water-Delivery Systems, Journal of Irrigation and Drainage Engineering, 116 (1990) 804-823.

[21] D.J. Molden, T.K. Gates, Performance Measures for Evaluation of Irrigation-Water-Delivery Systems, Journal of Irrigation and Drainage Engineering, 116 (1990) 804-823.

[22] D. Molden, M. Burton, M.G. Bos, Performance Assessment, Irrigation Service Delivery and Poverty Reduction: Benefits of Improved System Management, Irrigation and Drainage, 56 (2007) 307-320. https://doi.org/10.1002/ird.313

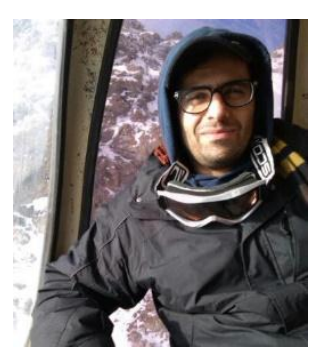

S. Mehdy Hashemy Shahdany was born in 1984 in Esfahan, Iran. He got his B.Sc. in agricultural engineering in Isfahan University of Technology in 2005. He got his M.Sc., and Ph.D. in hydraulic structure in Tarbiat Modares University respectively in 2007 and 2012.

Mehdy started his professional research career when he attended irrigation and drainage engineering department at Aburaihan Campus, University of Tehran, as a faculty member. He had a couple of international cooperation with Iowa flood center, University of Iowa, USA at 2015 and Agricultural and Biosystems Department in Oklahoma State University, Stillwater, OK, USA. At the moment his research interest is modern operational water management; water-energy nexus; and conjunctive operation of the surface and groundwater management. 